\title{
Association between melanoma and exposure to sex hormones in puberty: A possible window of susceptibility (Review)
}

\author{
FRANCESCA CAROPPO*, GIULIA TADIOTTO CICOGNA*, FRANCESCO MESSINA and MAURO ALAIBAC \\ Dermatology Unit, Department of Medicine, University of Padova, I-35128 Padova, Italy
}

Received July 18, 2020; Accepted December 16, 2020

DOI: $10.3892 / \operatorname{mco} .2021 .2228$

\begin{abstract}
The risk factors for melanoma in adolescents are similar to those in adults; however, it remains unclear whether these risk factors are also associated with melanoma in children. Epidemiological studies in the literature have reported a logarithmic increase in melanoma incidence after the age of 10 years. This may, in part, reflect the acute and chronic exposure to solar ultraviolet (UV) radiation during childhood. However, it appears unlikely that the cumulative exposure to UV radiation alone could explain such a sharp increase in melanoma incidence at the beginning of adolescence. It has been suggested that circulating sex hormones, the levels of which increase during puberty, may play a role in melanoma initiation and progression in predisposed individuals through binding to specific sex steroid receptors. The association between a longer cumulative exposure to sex hormones and the risk of melanoma may be supported by the reported epidemiological association between melanoma and several other sex hormone-related types of cancer, such as breast and prostate cancer, in which the enhanced exposure to androgens and estrogens was found to be directly associated with pubertal onset. Therefore, determining the association between pubertal onset and melanoma development may improve the current understanding of melanoma pathophysiology.
\end{abstract}

\section{Contents}

1. Introduction

2. Melanoma in children

3. Melanoma and sex hormones exposure

4. Role of estrogens

5. Role of androgens

6. Conclusions

Correspondence to: Professor Mauro Alaibac, Dermatology Unit, Department of Medicine, University of Padova, 4 Via Vincenzo Gallucci, I-35128 Padova, Italy

E-mail: mauro.alaibac@unipd.it

*Contributed equally

Key words: melanoma, sex hormones, puberty, estrogens, androgens

\section{Introduction}

Melanoma is a malignant skin tumor arising from the uncontrolled proliferation of melanocytes. These cells are localized in the stratum basale of the epidermis, where they produce melanin, a pigment that protects skin from ultraviolet (UV) radiation (1). Melanoma is the deadliest type of skin cancer and its incidence has been increasing worldwide over the past few decades. In the United States, it is the fifth most common cancer in both sexes, with an incidence of 21.8 per 100,000 individuals (2). However, the incidence of melanoma is not consistent across the entire population; for example, in the first two decades of life, the incidence of melanoma is rare, with children (age, 0-9 years) being minimally affected. Then, during adolescence, the incidence begins to increase in an age-dependent manner, until reaching its peak during the seventh and eighth decades of life (1).

In adults, the main risk factors for the development of melanoma may be intrinsic, such as fair skin and the total number of nevi present, or extrinsic, such as the amount of sun exposure, tanning bed usage, and immunosuppression due to the presence of comorbidities or systemic immunosuppressive treatments.

As regards the pediatric population, while the risk factors in adolescents are similar to those in adults, it is currently unknown whether these risk factors also apply to the risk of developing melanoma in children (3).

\section{Melanoma in children}

Pediatric melanoma is a rare entity, with only few case reports or case series reported to date. The possible role of environmental exposure in children remains under investigation, whereas family history has been established to be strongly associated with the occurrence of melanoma (4). Epidemiological studies in the literature have also reported a logarithmic increase in melanoma incidence after the age of 10 years $(2,5)$. This may, in part, reflect the acute and chronic exposure to solar UV radiation during childhood. However, it appears unlikely that the cumulative exposure to UV radiation alone can explain such a sharp increase in melanoma incidence at the beginning of adolescence (6).

\section{Melanoma and sex hormones exposure}

It has been suggested that hormonal changes during puberty may contribute to the increased melanoma incidence during 
adolescence. Puberty physiologically begins between the ages of 8 and 14 years, which is concurrent with the age in which the incidence of melanoma notably increases, after remaining at stably low levels during childhood (7). This parallel is further reinforced by another epidemiological observation: The fact that, in young adolescents, the increase in melanoma cases was reported to occur earlier in women compared with men $(6,8)$. This observation may be associated with the different time of onset of puberty in the two sexes, which occurs between the ages of 8 and 13 years in women and between the ages of 9 and 14 years in men (7).

As the progression of several types of cancer has been demonstrated to be hormone-dependent (9), a sudden increase in hormonal levels during adolescence may also affect melanomagenesis. This hypothesis relies on the increasing amount of data that are shedding light on the effects of sex steroids on melanocytes, possibly linking the hormonal changes of adolescence with an increased risk of melanoma.

The levels of circulating hormones increase during puberty and may play a role in melanoma initiation and progression in predisposed individuals through binding to specific sex steroid receptors. Estrogens exert their functions through estrogen receptor (ER) $\alpha$ and ER $\beta$, which are members of the nuclear receptor superfamily of transcription factors $(10,11)$. Both receptors share the same general structure, with three interacting functional domains: The N-terminal domain, DNA-binding domain and ligand-binding domain (LBD or $\mathrm{D} / \mathrm{E} / \mathrm{F})$. The $\mathrm{LBD}$ is also responsible for binding to co-regulatory and chaperone proteins. Concurrently, the same ligand may have different binding affinities for the ER $\alpha$ or ER $\beta$ subtypes $(10,11)$. Since endogenous estrogens, such as estradiol, bind to the two receptors with the same affinity, the net effect on the tissue varies based on the $E R \alpha / E R \beta$ ratio in the tissue and the microenvironment of the cells (11). Upon binding, both receptors activate a genomic and a non-genomic pathway (10). The non-genomic pathway involves the activation of two cytosolic signaling pathways, Ras/BRAF/MEK/ERK and PI3K/AKT, which exert more rapid effects (11). Of note, both non-genomic pathways are often mutated in melanoma, suggesting that sex hormones may be involved in melanoma pathogenesis (10). The physiological relevance of the cross-talk between the steroid-driven non-genomic pathway and MAPK activation was clearly demonstrated in ER $\alpha$ knockout model mice, as the association was not present in the absence of the $\mathrm{ER} \alpha$, suggesting an important interaction between these two pathways (10).

Furthermore, as multiple proteins involved in the signaling cascade of the ER $\alpha / \beta$ non-genomic pathways were found to be mutated in the majority of melanoma cases, both ERs, as well as the MAPK and PI3K signaling pathways may represent molecular targets against melanoma growth and progression $(10,11)$. In the genomic pathway, classic ER $\alpha / E R \beta s$ transmigrate into the nucleus and act as transcription factors, binding to specific DNA sequences and inducing the transcription of specific proteins. It is well known that ER $\alpha$ plays a role in tumorigenesis by promoting DNA transcription and stimulating cell proliferation, while ER $\beta$ exerts the opposite effect, exhibiting significant antitumor activity, altering the expression levels of the proteins involved in the $G_{1} / S$ transition of the cell cycle and causing cell cycle arrest $(10,11)$.
Accumulating clinical and molecular data have demonstrated that, in N-Ras-mutated melanoma cells, ER $\beta$ agonists exerted genomic effects at the nuclear level to modulate the expression levels of cell cycle-related proteins; therefore, ER $\beta$ may represent an effective molecular target for personalized therapeutic interventions in patients with melanoma carrying the N-Ras mutation $(10,11)$.

\section{Role of estrogens}

Epidemiological data indicate that estrogens play a protective role in melanoma, which was demonstrated through the reported prevalence of ER $\beta$ in melanocytic lesions, in contrast to ER $\alpha$, which is highly expressed on other epidermal cells. It was also found that ER $\beta$ was expressed in benign, as well as pre-malignant and malignant melanocytic neoplasms (12). Interestingly, ER $\beta$ expression levels were found to be downregulated in thicker and metastasizing melanomas, whereas ER $\beta$ expression levels were upregulated in melanomas diagnosed in women, who have been reported to have a better prognosis (11). This survival advantage is lost in women aged $>55$ years, which is consistent with the downregulation of ER $\beta$ expression following menopause. Therefore, ER $\beta$ may represent a positive prognostic factor for melanoma (13).

On the other hand, early onset of menarche and late menopause were reported to be associated with an increased risk of melanoma in a large, geographically dispersed population (14). The positive association between ambient UVR exposure and melanoma risk was particularly strong among women who had experienced menarche at an early age ( $\leq 10$ years), supporting the role of early-onset endogenous estrogen exposure for cutaneous melanoma development. Furthermore, a large French prospective study on a group of women reported that a reduced melanoma risk was associated with a decreased exposure to ovarian hormones. Women aged $>15$ years at menarche, those with an irregular menstrual cycle, women aged $<48$ years at natural menopause or those with a shorter reproductive life had a reduced risk of melanoma (15). Two studies have also indicated that hormone therapy may increase the risk of melanoma in postmenopausal women $(16,17)$. These findings suggested that women with a longer cumulative exposure to endogenous estrogens may be at a higher risk for melanoma development and may benefit from more frequent skin cancer screenings, particularly those living in areas with elevated levels of UVR radiation (14). Moreover, a delayed pubertal development may decrease the risk of developing melanoma. The association between the longer cumulative exposure to endogenous estrogens and the risk of melanoma may be supported by the proven epidemiological association between melanoma and breast cancer, one of the main types of cancer in which hormonal exposure is an established major risk factor. In fact, a large retrospective study revealed that, in a group of patients with melanoma, the risk of developing breast cancer was significantly increased compared with the risk of developing other types of cancer. In addition, in patients first diagnosed with breast cancer, the risk of melanoma development as a second malignancy was significantly higher compared with patients first diagnosed with other types of cancer (18). Goggins et al (19) also reported an epidemiological association between breast cancer and melanoma. 


\section{Role of androgens}

In addition to estrogen, accumulating evidence has emphasized the key role of excessive androgen production in breast cancer development. In fact, persistently elevated testosterone levels and increased aromatase activity were found to be responsible for increased estrogen production and subsequent cancer growth (20). Androgen receptor (AR) signaling has been implicated in the tumorigenesis of other types of cancer, including prostate, bladder, kidney and liver cancer (21). Regarding the association between endogenous androgens and melanoma risk, puberty may be an important biological window during which early-life androgen exposure may have both short- and long-term effects on melanomagenesis. In fact, a significant epidemiological association and a similar pathogenic pathway between melanoma and prostate cancer have been reported (22-24). An older age at sexual maturation appears to be associated with a reduced risk of prostate cancer development (25), and the AR is known to play an important role in the progression of prostate cancer $(23,24)$. Androgens also play an important role in the skin, particularly within melanocytes. In particular, testosterone was previously demonstrated to increase melanoma cell growth (26). Min et al (21) reported that, regardless of the basal levels of AR expression, the loss of AR activity triggered melanoma cell senescence, which subsequently limited carcinogenesis; this was due to the extensive chromosomal DNA breakage and the infiltration of macrophages into the tumor site. Moreover, in immune competent model mice, the loss of AR activity also led to cytotoxic T-cell activation (21). There is also evidence to suggest that the AR may promote melanoma metastasis via altering miRNA-539-3p/ubiquitin carboxyl-terminal hydrolase 13/microphthalmia-associated transcription factor/tyrosine-protein kinase receptor UFO signaling, which may be associated with melanoma cell survival $(23,24)$.

Androgens have also been suggested to indirectly affect melanoma development through their actions on the enzyme telomerase. Androgens were revealed to promote telomerase activity and telomere elongation $(27,28)$. Longer telomeres have been associated with an increased risk of melanoma; thus, through telomere elongation, androgens may prolong the lifespan of melanocytes and contribute to melanoma development (29). For these reasons, targeting androgen signaling in both sexes may improve the survival of patients with melanoma and suppress metastasis (30).

\section{Conclusions}

Accumulating evidence has suggested that the increased levels of sex hormones, which characterizes adolescence, may explain the observed increase in the number of cases with diagnosed melanoma following puberty. Several previous studies have shed light on the role of the exposure to sex hormones in the development of several types of cancer and, more recently, in melanomagenesis. Thus, determining the association between the onset of puberty and melanoma development may improve the current understanding of melanoma pathophysiology.

\section{Acknowledgements}

Not applicable.

\section{Funding}

No funding was received.

\section{Availability of data and materials}

Not applicable.

\section{Authors' contributions}

All authors (FC, GTC, FM and MA) have made substantial contributions to conception and design, interpretation of data, participated in drafting the article and gave final approval of the version to be submitted and any revised version.

\section{Ethics approval and consent to participate}

Not applicable.

\section{Patient consent for publication}

Not applicable.

\section{Competing interests}

The authors declare that they have no competing interests.

\section{References}

1. Matthews NH, Li WQ, Qureshi AA, Weinstock MA and Cho E: Epidemiology of Melanoma. In: Cutaneous Melanoma: Etiology and Therapy [Internet]. Ward WH and Farma JM (eds). Codon Publications, Brisbane (AU), Dec 21, 2017.

2. Paulson KG, Gupta D, Kim TS, Veatch JR, Byrd DR, Bhatia S, Wojcik K, Chapuis AG, Thompson JA, Madeleine MM and Gardner JM: Age-specific incidence of melanoma in the United States. JAMA Dermatol 156: 57-64, 2020.

3. Eggen CAM, Durgaram VV, van Doorn R, Mooi WJ, Pardo LM, Pasmans SGMA and Hollestein LM: Incidence and relative survival of melanoma in children and adolescents in the Netherlands, 1989-2013. J Eur Acad Dermatol Venereol 32: 956-961, 2018.

4. Whiteman DC, Valery P, McWhirter W and Green AC: Risk factors for childhood melanoma in Queensland, Australia. Int J cancer 70: 26-31, 1997.

5. Dean PH, Bucevska M, Strahlendorf C and Verchere C: Pediatric melanoma: A 35-year population-based review. Plast Reconstr Surg Glob Open 5: e1252, 2017.

6. Strouse JJ, Fears TR, Tucker MA and Wayne AS: Pediatric melanoma: Risk factor and survival analysis of the Surveillance, Epidemiology and End Results database. J Clin Oncol 23: 4735-4741, 2005.

7. Farello G, Altieri C, Cutini M, Pozzobon G and Verrotti A: Review of the literature on current changes in the timing of pubertal development and the incomplete forms of early puberty. Front Pediatr 7: 147, 2019.

8. Berg P and Lindelof B: Differences in malignant melanoma between children and adolescents. A 35-year epidemiological study. Arch Dermatol 133: 295-297, 1997.

9. Folkerd EJ and Dowsett M: Influence of sex hormones on cancer progression. J Clin Oncol 28: 4038-4044, 2010.

10. Dika E, Patrizi A, Lambertini M, Manuelpillai N, Fiorentino M, Altimari A, Ferracin M, Lauriola M, Fabbri E, Campione E, et al: Estrogen receptors and melanoma: A review. Cells 8: 1463, 2019.

11. Marzagalli M, Marelli MM, Casati L, Fontana F, Moretti RM and Limonta P: Estrogen receptor $\beta$ in melanoma: From molecular insights to potential clinical utility. Front Endocrinol (Lausanne) 7: 40, 2016. 
12. Schmidt AN, Nanney LB, Boyd AS, King LE and Ellis DL: Oestrogen receptor-beta expression in melanocytic lesions. Exp Dermatol 15: 971-980, 2006.

13. de Giorgi V, Gori A, Gandini S, Papi F, Grazzini M, Rossari S, Simoni A, Maio V and Massi D: Oestrogen receptor beta and melanoma: A comparative study. Br J Dermatol 168: 513-519, 2013.

14. Donley GM, Liu WT, Pfeiffer RM, McDonald EC, Peters KO, Tucker MA and Cahoon EK: Reproductive factors, exogenous hormone use and incidence of melanoma among women in the United States. Br J Cancer 120: 754-760, 2019.

15. Kvaskoff M, Bijon A, Mesrine S, Boutron-Ruault MC and Clavel-Chapelon F: Cutaneous melanoma and endogenous hormonal factors: A large French prospective study. Am J Epidemiol 173: 1192-1202, 2011.

16. Holly EA, Cress RD and Ahn DK: Cutaneous melanoma in women: Ovulatory life, menopause, and use of exogenous estrogens. Cancer Epidemiol Biomarkers Prev 3: 661-668, 1994.

17. MacKie RM and Bray CA: Hormone replacement therapy after surgery for stage 1 or 2 cutaneous melanoma. Br J Cancer 90: 770-772, 2004

18. Caini S, Radice D, Tosti G, Spadola G, Cocorocchio E, Ferrucci PF, Testori A, Pennacchioli E, Fargnoli MC, Palli D, et al: Risk of second primary malignancies among 1537 melanoma patients and risk of second primary melanoma among 52354 cancer patients in Northern Italy. J Eur Acad Dermatol Venereol 30: 1491-1496, 2016.

19. Goggins W, Gao W and Tsao H: Association between female breast cancer and cutaneous melanoma. Int J Cancer 111: 792-794, 2004

20. Secreto G, Girombelli A and Krogh V: Androgen excess in breast cancer development: Implications for prevention and treatment. Endocr Relat Cancer 26: R81-R94, 2019.

21. Min M, Ghosh S, Tavernari D, Katarkar A, Clocchiatti A, Mazzeo L, Samarkina A, Epiney J, Yu YR, Ho PC, et al: Sustained androgen receptor signaling is a determinant of melanoma cell growth potential and tumorigenesis. J Exp Med 8: e20201137, 2021.
22. Goldenberg A, Jiang SI and Cohen PR: A possible association between melanoma and prostate cancer. Results from a case-control-study. Cancers (Basel) 7: 670-678, 2015.

23. Rampen FH and Mulder JH: Malignant melanoma: An androgendependent tumour? Lancet 1: 562-564, 1980.

24. Slominski A, Tbin DJ, Shibahara S and Wortsman J: Melanin pigmentation in mammalian skin and its hormonal regulation. Physiol Rev 84: 1155-1228, 2004.

25. Bonilla C, Lewis SJ, Martin RM, Donovan JL, Hamdy FC, Neal DE, Eeles R, Easton D, Kote-Jarai Z, Al Olama AA, et al: Pubertal development and prostate cancer risk: Mendelian randomization study in a population-based cohort. BMC Med 14: 66, 2016.

26. Allil PA, Visconti MA, Castrucci AM and Isoldi MC: Photoperiod and testosterone modulate growth and melanogenesis of S91 murine melanoma. Med Chem 4: 100-105, 2008.

27. Kim SH, Richardson M, Chinnakannu K, Bai VU, Menon M, Barrack ER and Reddy GP: Androgen receptor interacts with telomeric proteins in prostate cancer cells. J Biol Chem 285: 10472-10476, 2010.

28. Zhou J, Richardson M, Reddy V, Menon M, Barrack ER, Reddy GP and Kim SH: Structural and functional association of androgen receptor with telomeres in prostate cancer cells. Aging 5: 3-17, 2013.

29. Nan H, Du M, De Vivo I, Manson JE, Liu S, McTiernan A, Curb JD, Lessin LS, Bonner MR, Guo Q, et al: Shorter telomeres associate with a reduced risk of melanoma development. Cancer Res 71: 6758-6763, 2011.

30. Hsueh EC, Gupta RK, Lefor A, Reyzin G, Ye W and Morton DL: Androgen blockade enhances response to melanoma vaccine. J Surg Res 110: 393-398, 2003. 